\title{
Baseline Fetal Heart Rate
}

National Cancer Institute

\section{Source}

National Cancer Institute. Baseline Fetal Heart Rate. NCI Thesaurus. Code C92741.

The number of fetal cardiac beats per minute, considered as the reference value ag ainst which measurements in the future can be made. 